\title{
.
}

\section{EL RESPALDO DE CESCE EN TIEMPOS DE COVID, IMPULSO ESENCIAL PARA LA INTERNACIONALIZACIÓN DE LAS EMPRESAS}

Con motivo de la crisis provocada por la COVID-19, en coordinación con la Secretaría de Estado de Comercio, CESCE ha puesto en funcionamiento medidas específicas encaminadas a atender las necesidades de las empresas españolas que llevan a cabo una actividad internacional. Entre otras actuaciones, la Cuenta del Estado de CESCE ha gestionado una primera Línea Extraordinaria de Cobertura para la Financiación de Créditos de Circulante a empresas internacionalizadas. Una vez agotada esta primera línea, en la que se han cubierto créditos por valor de 1.377,5 millones de euros, se está gestionado actualmente otra segunda, en la que, hasta la fecha, se han recibido por parte de las entidades financieras casi seiscientas solicitudes de cobertura de créditos por valor de 923 millones de euros. La gestión de estas dos líneas está suponiendo para la Cuenta del Estado de CESCE un esfuerzo sin precedentes al tener que adecuar la forma de trabajar al elevado volumen de solicitudes. Se han redoblado los esfuerzos para simplificar y mecanizar los procesos realizando desarrollos tecnológicos que permitan apoyar cada vez a un número mayor de empresas.

Palabras clave: CESCE, pymes, créditos de circulante, internacionalización, exportación, seguros derivados de la internacionalización, cobertura de riesgos de crédito, cobertura de avales, cobertura de riesgos por cuenta del Estado, contratos internacionales.

Clasificación JEL: F34, G28, L53.

\section{Introducción}

Desde los primeros días de 2020, en que empezó a hacer sombra la pandemia por todo el mundo, hasta hoy se han dedicado esfuerzos sin precedentes desde todos los ámbitos de la sociedad, de los Gobiernos a todos los niveles y

\footnotetext{
* Jefa de la Unidad de Pymes de la Cuenta del Estado de CESCE. Versión de abril de 2021.

DOI: https:/doi.org/10.32796/bice.2021.3135.7198
}

de las empresas para intentar recuperar la normalidad de la forma más acelerada dentro de las posibilidades que nos ha brindado la crisis sanitaria en la que todavía seguimos inmersos.

Lo que inicialmente fue una crisis sanitaria se trasladó rápidamente al ámbito económico a medida que los cierres de las distintas economías interrumpían las cadenas de suministro, en un primer momento, y la actividad económica de prácticamente todos los sectores -y en casi todos los países-, poco después. 
La puesta en marcha de respuestas coordinadas y rápidas para garantizar la recuperación ha sido crucial: bancos centrales y Gobiernos de todo el mundo han implementado paquetes de facilidades fiscales, financieras y ayudas de todo tipo para las empresas que han permitido mitigar los efectos de esta crisis económica mundial.

\section{Entorno macro en el que nos encontramos}

La epidemia originada en la ciudad china de Wuhan, en diciembre de 2019, se extendió por todo el planeta en apenas cuatro meses. Para frenar la curva de contagios y combatir el colapso de los sistemas sanitarios se han implantado cuarentenas, confinamientos y cierres de regiones enteras. En función del país, estas medidas han influido en la actividad económica de millones de personas y han desembocado en una caída extraordinaria en el PIB mundial.

El impacto ha variado en función de la capacidad de los países para controlar la incidencia del virus y del peso que, los sectores que más han sufrido, tienen en su estructura económica. Los países que adoptaron estrategias contundentes en la fase inicial de la crisis sanitaria han logrado reducir al mínimo la incidencia del virus $\mathrm{y}$, como resultado, recuperar con mayor rapidez el funcionamiento normal de la economía. El ejemplo por excelencia es China, que ha crecido un $2 \%$ en 2020; otros países, como Australia, Nueva Zelanda, Corea del Sur o Vietnam, han seguido estrategias similares.

De forma generalizada, los bancos centrales han implantado un amplio abanico de medidas que han facilitado la financiación de la política fiscal y el crédito a las empresas. La intervención de los bancos centrales ha sido inédita, con actuaciones rápidas y masivas. La política económica se ha volcado en proteger, en la media de lo posible, el tejido productivo, con el fin de evitar al máximo el daño estructural. En el terreno fiscal se han aplicado programas de estímulo, destinados a proteger los ingresos de las economías familiares y a aliviar las necesidades de liquidez de las empresas por diversas vías, que incluyen reducciones de los costes laborales, moratorias impositivas y la concesión de garantías públicas a créditos concedidos por las instituciones financieras.

La crisis económica no terminará hasta que no se controle la crisis sanitaria, y, hoy por hoy, las vacunas constituyen la única esperanza de frenar la situación. Las campañas de vacunación han comenzado a principios de este año y, con diferente ritmo de avance, se espera que en los países desarrollados buena parte de la población esté inmunizada para el verano de 2021.

Así pues, 2021 debe ser el año del comienzo de la recuperación si se cumplen las anteriores premisas acerca de la vacunación. Más allá de la cifra de crecimiento, el principal interrogante, una vez superada la pandemia, será la valoración del daño al tejido empresarial de los distintos países, puesto que las medidas adoptadas se han orientado a reducir los problemas de liquidez, pero la prolongación en el tiempo de la crisis tendrá un impacto también sobre la solvencia. Las empresas que sobrevivan se van a encontrar, además, con un problema de sobreendeudamiento. De hecho, el elevadísimo volumen de la deuda, pública y privada, constituye uno de los principales riesgos a los que se enfrentaba ya la economía mundial. En el caso de los países desarrollados, a partir de este año, un volumen de deuda pública por encima del $100 \%$ del PIB dejará de ser una excepción. 
En España se cumple un año desde que se decretó el estado de alarma, paralizándose en gran medida su actividad para tratar de controlar los contagios provocados por el virus SARSCoV-2. Las restricciones de movilidad han provocado la parálisis de la industria turística. En el caso de España, segundo destino turístico del mundo, esto ha supuesto una pérdida de ingresos del orden del $5 \%$ del PIB.

La crisis de la COVID-19 ha sido de una magnitud inaudita. Nunca antes en tiempos de paz se había producido un desplome de la actividad como el que se registró en 2020. EI PIB cayó un $11 \%$ en el conjunto del ejercicio, llegando incluso a situarse un $22 \%$ por debajo del nivel precrisis en el segundo trimestre del año. Ni siquiera en la crisis de 2008 el desplome económico fue de tal dimensión (la caída fue «apenas» del $9 \%$ ), sin que pueda compararse la crisis actual con la sufrida entonces, dado que la naturaleza de ambas crisis es totalmente distinta. Mientras que en el año 2008 las dificultades comenzaron en los mercados financieros $y$, posteriormente, contagiaron al conjunto de la economía, en 2020 ha sido la pandemia provocada por el virus SARS-CoV-2 el desencadenante de esta situación.

La deuda pública, por su parte, ha aumentado hasta el 117,1\% del PIB, si bien España no está teniendo problemas para cubrir sus necesidades de financiación gracias al apoyo que presta el Banco Central Europeo. El sector exterior también ha experimentado un durísimo impacto. Las exportaciones de bienes han registrado un retroceso del $10 \%$ frente a 2019 . Pero lo verdaderamente grave para la economía española ha sido el desplome del turismo. En 2020 España recibió 19 millones de turistas, un $77,3 \%$ menos que en 2019 . Como consecuencia, la balanza de servicios, tradicionalmente en superávit, se ha hundido a terreno negativo. Ciertamente, la importancia del turismo en la estructura productiva del país, que supone alrededor de un $12 \%$ del PIB, explica el mayor impacto en la balanza comercial española en comparación con otros países de la zona euro.

Dado el peso del sector turístico en la economía española, actividad en la que incide de forma especial el cumplimiento de las normas de distancia social, el desempeño económico futuro dependerá única y exclusivamente del éxito en el control del virus, lo que, a su vez, vendrá determinado por la evolución de la campaña de vacunación. Solo en ese momento se podrá comenzar a hablar de recuperación sostenida de la economía. Si se consigue el objetivo de vacunar al $70 \%$ de la población antes del verano, los primeros signos positivos en la coyuntura económica podrían observarse hacia la segunda mitad del año, cuando se espera un notable repunte de la actividad.

Además de la reactivación del sector turístico, un marco de actuación clave en el que proporcionar respuestas adaptadas a las necesidades actuales en el caso de la economía española es el sector exterior. De hecho, este fue el motor para salir de la última crisis financiera vivida en nuestro país.

\section{Medidas adoptadas por CESCE en el contexto COVID}

En CESCE, como gestores de instrumentos de apoyo a las empresas internacionalizadas o en proceso de internacionalización, llevamos casi cincuenta años apoyando al sector exterior. En este tiempo hemos ido adaptando nuestros productos y nuestra forma de trabajar a lo que en cada momento necesitan las empresas españolas en su actividad internacional. 
Con motivo de la crisis provocada por el coronavirus se han puesto en funcionamiento medidas específicas encaminadas a atender las necesidades del sector exportador y hacer todo lo posible para contribuir a solventar las dificultades a las que se enfrentan las empresas españolas, grandes o pequeñas, en los mercados internacionales en estos momentos tan extraordinarios.

En coordinación con la Secretaría de Estado de Comercio, CESCE ha llevado a cabo las siguientes actuaciones para contribuir a paliar los efectos de la COVID-19 sobre las empresas españolas que llevan a cabo una actividad internacional.

\subsection{Primera Línea Extraordinaria de Cobertura Aseguradora de Créditos de Circulante}

Ante lo extraordinario de la situación acaecida por el coronavirus, la Administración instruyó a CESCE a lanzar una Línea Extraordinaria de Cobertura para Financiación de Créditos de Circulante para empresas internacionalizadas de hasta 2.000 millones de euros en dos tramos. La línea quedó regulada mediante el RDL $8 / 2020$, de 17 de marzo, sobre medidas urgentes extraordinarias para hacer frente al impacto económico y social de la COVID-19 y el RDL $25 / 2020$, de 3 de julio, que amplía el ámbito de la línea, incorporando como elegibles a empresas cotizadas que en la primera norma habían quedado excluidas. Este programa está amparado por la Comunicación de la Comisión Europea relativa al Marco Temporal relativo a las medidas de ayuda estatal destinadas a respaldar la economía en el contexto del actual brote de COVID-19 (COM 2020/C 91 I/01).

La línea, sujeta a la normativa de ayudas de Estado de la Unión Europea, estaba dirigida a empresas españolas consideradas pymes, así como a otras empresas de mayor tamaño, incluidas cotizadas, en las que concurrieran las siguientes circunstancias: que se tratara de empresas internacionalizadas o en proceso de internacionalización que se enfrentaran a un problema de liquidez o de falta de acceso a la financiación como resultado del impacto de la crisis de la COVID-19 en su actividad económica. Para ser consideradas dentro de esta categoría, las empresas debían cumplir al menos uno de los siguientes requisitos:

- Que su negocio internacional, reflejado en su última información financiera disponible, representara al menos un tercio (33\%) de su cifra de negocios.

- Empresas que fueran exportadoras regulares (aquellas empresas que hubieran exportado regularmente durante los últimos cuatro años).

Quedaban expresamente excluidas de la línea las empresas que se encontraran en cualquiera de las siguientes situaciones:

- Que aparecieran en situación de morosidad en la consulta a los ficheros de la Central de Información de Riesgos del Banco de España (CIRBE).

- Que presentaran incidencias de impago con empresas del Sector Público o deudas con la Administración registradas con anterioridad al 31 de diciembre de 2019.

- Empresas en situación concursal o preconcursal.

Además, quedaban también excluidas las empresas en situación de crisis a 31 de diciembre de 2019 , conforme a los criterios establecidos $\triangleright$ 
en el artículo 2 (18) del Reglamento de la Comisión n. ${ }^{\circ}$ 651/2018, de 17 de junio de 2014, por el que se declaran determinadas categorías de ayudas compatibles con el mercado interior.

Esta línea extraordinaria comparte muchas características, en cuanto a las coberturas que ofrece, con la póliza tradicional de CESCE de Créditos de Circulante; sin embargo, hay una diferencia esencial: mientras que la póliza tradicional está concebida para cubrir el riesgo de impago de un crédito que tiene por objeto financiar a una empresa española para llevar a cabo uno o varios contratos o proyectos de exportación o de internacionalización, bajo esta línea de cobertura no era necesario que los créditos de circulante otorgados a las empresas españolas tuvieran relación directa con un contrato internacional, siempre que respondieran a nuevas necesidades de financiación derivadas de la crisis sanitaria provocada por la COVID-19 y no a situaciones previas a la crisis actual.

CESCE, en esta modalidad de cobertura, cubre al banco que concede la financiación frente al riesgo de impago del crédito por parte del deudor, por lo que el objetivo es facilitar a las empresas que cumplen los requisitos de elegibilidad un mayor acceso a la financiación para cubrir sus necesidades de circulante.

El mismo RDL preveía la aplicación de mecanismos ágiles de decisión para las solicitudes con cargo a la línea. En este sentido, con un porcentaje de cobertura máximo de las operaciones aseguradas bajo esta línea del $80 \%$, se decidió que aquellas solicitudes para las que las entidades financieras solicitaran porcentajes de cobertura inferiores al $70 \%$ y, en especial, en aquellos casos en los que la suma asegurada fuera igual o inferior a 10 millones de euros, la aprobación del riesgo sería automática.

Aunque es muy pronto para valorar el comportamiento de los riesgos asumidos con cargo a esta línea, se han contratado 752 pólizas, que han dado cobertura a créditos por valor de 1.377,5 millones de euros. La suma asegurada por CESCE asciende a 970,2 millones de euros.

Más de veinte entidades financieras han participado en este programa, encabezadas, por número de solicitudes, por Bankinter, Banco Santander, Bankia, Abanca y Deutsche Bank.

En cuanto a las empresas beneficiarias de los créditos asegurados por CESCE, cabe señalar que dos terceras partes de las pólizas $\triangle$

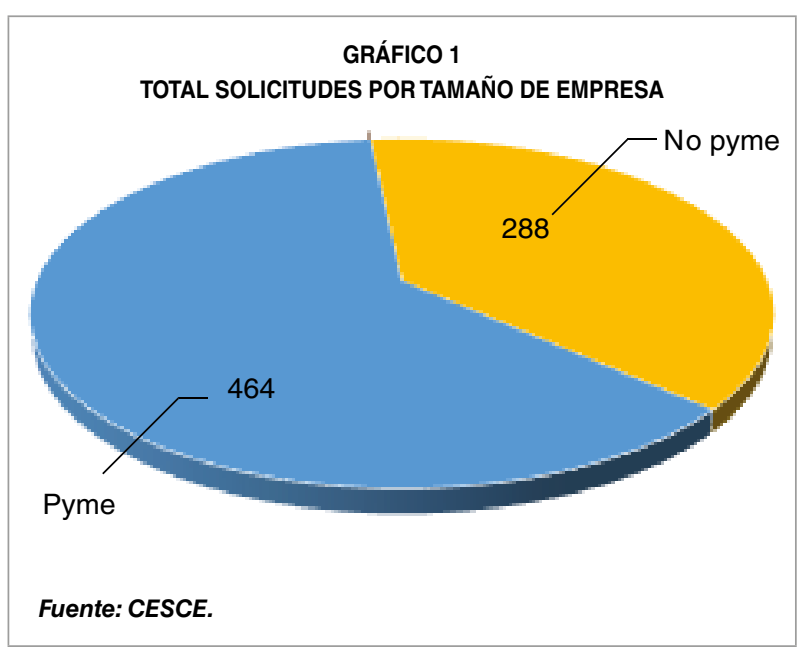

TABLA 1

SEGURO CESCE

\begin{tabular}{|c|c|c|c|}
\hline & Operaciones & Suma total (euros) & Cobertura promedio (\%) \\
\hline Total operaciones contratadas & 752 & 970.222 .727 & 70,6 \\
\hline Pyme & 464 & 287.364.779 & 71,3 \\
\hline 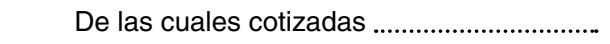 & 0 & - & - \\
\hline No pyme ........................ & 288 & 682.857 .948 & 69,5 \\
\hline 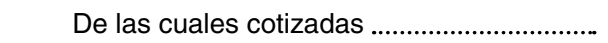 & 10 & 107.630 .000 & 71,5 \\
\hline
\end{tabular}




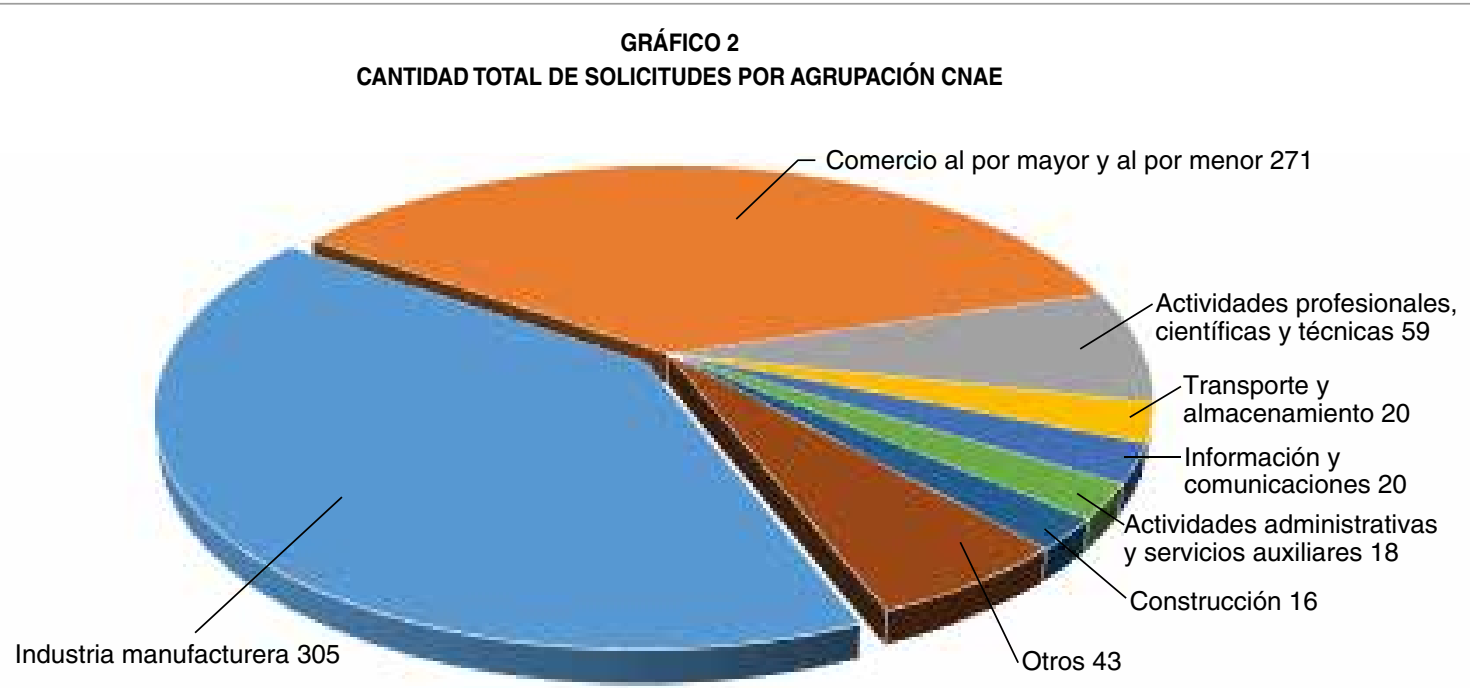

Fuente: CESCE.

contratadas han correspondido a créditos otorgados a pymes, frente a un tercio para empresas de mayor tamaño (de estas, sólo diez operaciones han tenido como beneficiarias de los créditos a empresas cotizadas, lo que representa un $11 \%$ del total de la cifra contratada).

Por sector de actividad, según la Clasificación Nacional de Actividades Económicas (CNAE), las empresas beneficiarias se dedican a la industria manufacturera; al comercio al por mayor y al por menor; a actividades profesionales, científicas y técnicas; a la construcción; transporte y almacenamiento; a la información y comunicaciones; $y$ a actividades administrativas y servicios auxiliares, entre otros.

\subsection{Segunda Línea Extraordinaria de Cobertura Aseguradora de Créditos de Circulante}

Una vez agotado el plazo para imputar operaciones con cargo a la primera Línea Covid, dado que persistían las necesidades para las que fue creada, y considerando la ampliación del Marco Temporal de ayudas de Estado que la amparaba, la Comisión Delegada del Gobierno para Asuntos Económicos aprobó, el 23 de octubre de 2020, también con carácter extraordinario, una nueva Línea Covid de Cobertura de Créditos de Circulante por valor de 1.000 millones de euros (Línea Covid II) que diera continuidad a la anterior.

Esta segunda línea, cuyos términos esenciales replican los descritos en el punto anterior ${ }^{1}$, comenzó a funcionar en octubre del año pasado y, según la información disponible a 29 de abril de 2021, se han recibido por parte de las entidades financieras casi seiscientas solicitudes de cobertura de créditos por valor de 923 millones de euros, que suponen 628 millones en términos de suma asegurada para CESCE. Del total de estas operaciones ya se han contratado, conforme a la última información disponible en el momento en que se escriben estas líneas, $\square$

1 De acuerdo con las prórrogas al Marco Temporal de la UE, se han modificado las fechas de vigencia de las líneas o de algunos de los criterios de elegibilidad y cálculo de importes. 
274 pólizas, por un importe de 271 millones de euros de seguro emitido, que respaldan créditos por valor de 386 millones de euros.

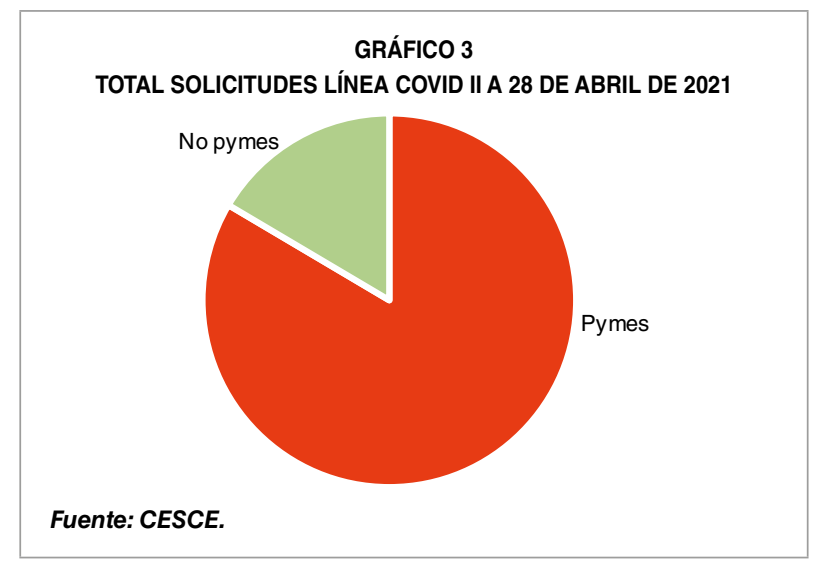

Hasta la fecha, el $84 \%$ de las solicitudes recibidas bajo la Línea II responden de créditos cuyos beneficiarios son pymes (es decir, una proporción mayor que la media de la Línea Covid I, en la que el peso de las pymes fue del $62 \%$, en número de operaciones).

Las Líneas Covid I y Covid II han supuesto para la Cuenta del Estado de CESCE un esfuerzo sin precedentes al tener que adecuar nuestra forma de trabajar al elevado volumen de solicitudes que se están gestionando al amparo de ambas líneas.

Si al cierre de los dos ejercicios anteriores, 2018 y 2019, se habían contratado 357 y 291 pólizas respectivamente, con base en la actividad habitual de CESCE, a 31 de diciembre de 2020 se habían formalizado 1.058 pólizas, lo que da una idea de lo que representa la suscripción de operaciones al amparo de estas líneas en relación con la actividad tradicional de la Cuenta del Estado de la compañía.

Conseguir las cifras de contratación mencionadas anteriormente ha sido posible gracias a la simplificación y mecanización de nuestros procesos. Hemos realizado desarrollos tecnológicos que sin duda nos permiten estar hoy en mejor posición para seguir creciendo en número de operaciones y, por tanto, en número de empresas a las que podemos apoyar de una forma ágil y eficaz.

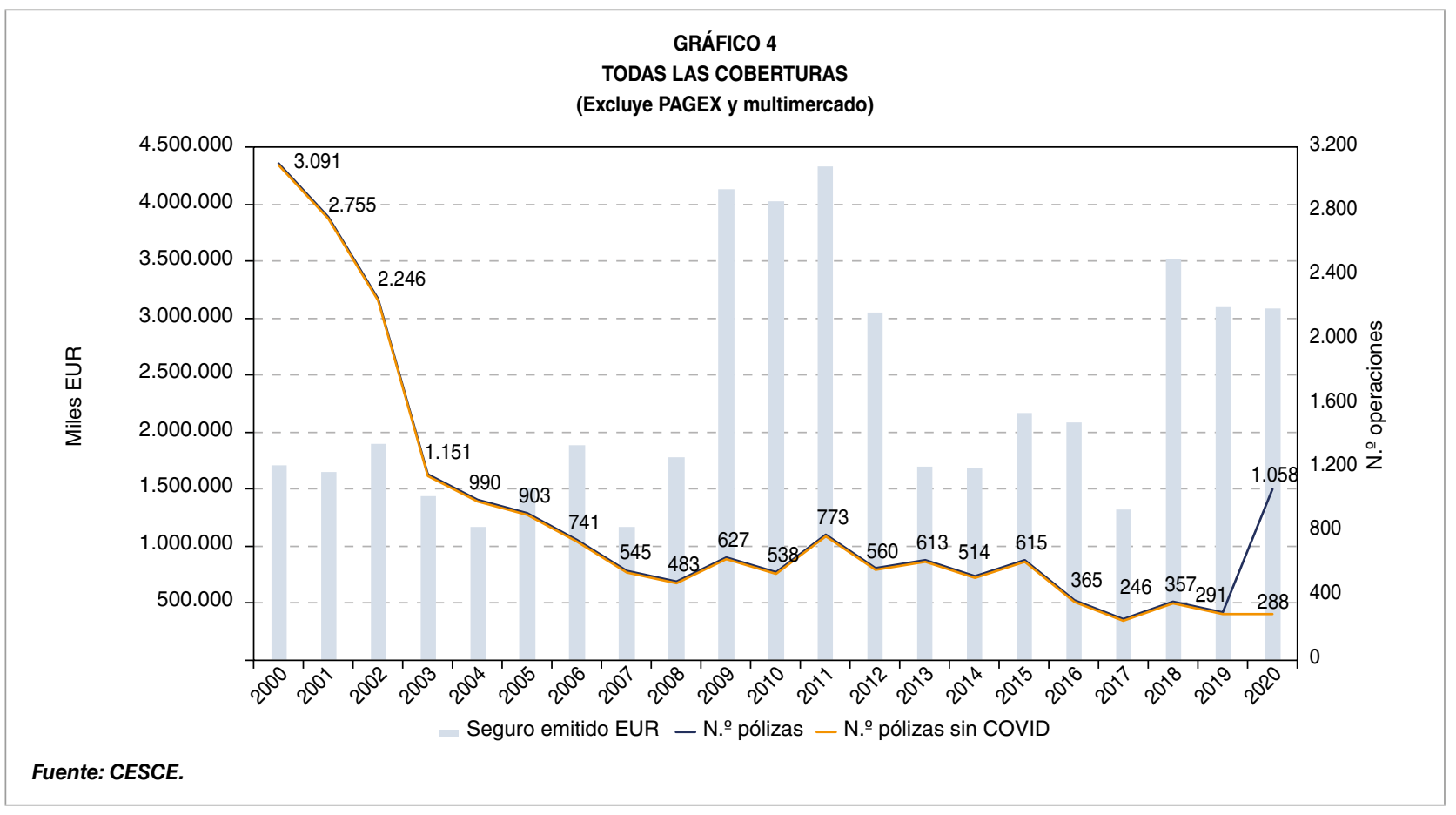




\subsection{Apoyo especial a las pymes}

Además de las líneas extraordinarias de créditos de circulante que se han mencionado anteriormente y cuyos beneficiarios en gran medida son las pymes, se han llevado a cabo otra serie de actuaciones encaminadas a apoyar a las empresas de menor tamaño.

Una de esas medidas ha sido el refuerzo de la Línea CESCE de Avales y Circulante para pymes y empresas no cotizadas, cuya dotación se elevó hasta los 500 millones de euros, otorgándole además carácter revolving. En 2020 el presupuesto de esta línea se reforzó en dos ocasiones. La primera, a los dos meses de confinamiento, en el mes de mayo, cuando se aprobó un incremento de 100 millones de euros, que elevó a 400 millones de euros la dotación existente en ese momento. El segundo incremento tuvo lugar pocos meses después, en octubre, con un aumento de otros 100 millones de euros, lo que dejó la línea en los 500 millones de euros actuales.

Con el incremento en esta línea, la Cuenta del Estado de CESCE ha contado con un instrumento mejor dotado para cumplir con su labor de respaldo a las pymes que operan en el mercado exterior. Un apoyo indispensable en estos momentos, que viene a sumarse al paquete de medidas aprobadas por el Gobierno en el contexto de la COVID-19 para volver a la senda del crecimiento económico y de la creación de empleo.

La línea forma parte de un abanico de productos y coberturas que CESCE pone a disposición de las pequeñas y medianas empresas, directamente o indirectamente a través de los bancos. En este caso, los avales o créditos de circulante que se benefician de esta línea se destinan a operaciones de internacionalización de pymes o empresas no cotizadas internacionalizadas o en proceso de internacionalización que, gozando de una buena capacidad técnica, puedan tener un acceso limitado al crédito bancario por distintos motivos, que van desde que exista una desproporción entre el importe de los avales o el crédito necesario para financiar un contrato y su balance hasta que se trate de empresas de reciente creación.

Las operaciones con cargo a esta línea incluyen coberturas en las modalidades de avales a emisores, fianzas a exportadores y créditos de circulante asociadas a la ejecución de contratos internacionales de pymes y empresas no cotizadas que necesitan ordenar la emisión de avales técnicos, así como financiación a corto plazo para ejecutar sus proyectos. Esta línea de avales constituye, por tanto, una herramienta esencial para impulsar la actividad de este tipo de empresas en el exterior que, en estos momentos, requieren más apoyo que nunca para mantenerse o lanzarse al mercado internacional y obtener nuevos contratos que les permitan mantener la actividad que vienen desarrollando.

Desde la creación de esta línea se han estudiado más de 267 proyectos con cargo a la misma, con un considerable efecto multiplicador, ya que, con la cobertura de CESCE, ha sido posible apoyar contratos internacionales de empresas españolas por un valor superior a los 3.000 millones de euros.

Esta línea ha permitido a muchas empresas acceder a proyectos y contratos de internacionalización que de otra forma no habrían podido realizar. Empresas que estaban iniciando su proceso de internacionalización y que no encontraban posibilidades en el mercado para poder emitir los avales que les requerían han podido, gracias al seguro de CESCE con cargo a la línea, firmar y ejecutar esos contratos, y $\triangleright$ 
su situación financiera se ha visto claramente favorecida, al mismo tiempo que ampliaban sus mercados. Asimismo, empresas que tenían sus líneas de avales con los bancos casi totalmente dispuestas han podido liberar parte de ellas gracias a la línea y así asegurar nuevos proyectos.

\subsection{Otras medidas para paliar los efectos de la COVID-19 en las empresas}

Con fecha 22 de abril de 2020, la Comisión de Riesgos por Cuenta del Estado de CESCE aprobó una serie de medidas, que se resumen a continuación, para flexibilizar la operativa habitual con relación a cierto tipo de solicitudes, tanto de operaciones nuevas como de actuaciones sobre operaciones en cartera, ante la previsión de que la crisis de la COVID-19 pudiera resultar en un incremento de solicitudes de modificación de coberturas ya existentes. Con ello se pretendía facilitar a las empresas españolas terminar sus contratos de exportación y a los deudores extranjeros atender sus obligaciones de pago en un entorno de caídas de ingresos o de dificultades extraordinarias.

Con este objetivo se han admitido y tramitado solicitudes de cobertura sobre riesgos relacionados con operaciones cuya ejecución había sido iniciada por el exportador sin prever que existiera una cobertura relacionada. Esto difiere de la práctica habitual, en la que, con carácter general, no se admiten esas operaciones ya iniciadas sin seguro salvo en casos excepcionales.

La crisis de la COVID-19 ha provocado que muchos exportadores que estaban ejecutando contratos sin cobertura directa o sin financiación asegurada asociada se hayan visto en la obligación de otorgar prórrogas, bien en los términos de pago, bien en el periodo de ejecución de los contratos (por la incapacidad de ejecutarlos en la situación provocada por la pandemia), encontrándose con un riesgo en cartera con el que no contaban y que posteriormente han considerado necesario asegurar.

A pesar de las numerosas llamadas a que la banca mantuviera sus niveles de apoyo a las empresas, debido a la situación provocada por la COVID-19, era previsible que asistiéramos a una contracción de las líneas de crédito y avales a las empresas similar a la que se produjo en la última crisis. En este contexto, otra medida adicional que se aprobó fue considerar, para estos productos, y en el caso de que las entidades financieras lo solicitaran, porcentajes de cobertura del riesgo superiores al $50 \%$, en modalidades de cobertura en las que tradicionalmente no se otorgan (con el objetivo de compartir con las entidades financieras los riesgos derivados de la operación).

Por otro lado, con el propósito de ayudar a minimizar las pérdidas de las empresas exportadoras intervinientes en las operaciones y de facilitar el cumplimiento de sus obligaciones, se tomaron una serie de medidas para el tratamiento de las solicitudes de ampliación de plazos y de reestructuración de términos de pago que afectaran a operaciones ya en cartera, tanto de aquellas en las que los contratos de exportación subyacentes estaban todavía en fase de ejecución como de aquellas en las que el contrato de exportación estaba completamente ejecutado y se encontraban en la fase de repago del crédito asociado.

En el momento en que se tomaron estas medidas anticipábamos que, a medida que la pandemia obligara a paralizar la actividad económica en los países de destino, se presentaría la necesidad de reestructurar créditos ya en cobertura $O$ de realizar modificaciones $D$ 
contractuales de distinto tipo en las operaciones que ya teníamos en cartera con objeto de evitar impagos o incumplimientos de las partes.

Por último, dentro de este capítulo se acordaron distintas actuaciones con el objetivo de agilizar la tramitación y toma de decisiones en aquellos casos en los que se solicitara una ampliación del seguro derivada de la necesidad de acomodar los retrasos en la ejecución de los contratos de exportación asociados a las coberturas en vigor, así como de facilitar las reestructuraciones de deuda para aquellas operaciones en fase de amortización del crédito asegurado.

Aunque estas medidas de flexibilización sobre nuestra operativa habitual fueron introducidas muy temprano, como se ha indicado, lo cierto es que durante 2020 no han resultado tan necesarias como se anticipaba. No ha sido hasta finales de ese año y los primeros meses de este cuando se ha comenzado a recibir un número creciente de solicitudes de reestructuración de operaciones en cartera. Aun así, el comportamiento de las operaciones ya asumidas sigue siendo mejor del que cabía esperar.

\section{Cobertura de riesgos de crédito a corto plazo}

Dentro de las medidas adoptadas por la Unión Europea para flexibilizar el apoyo de los Estados a la economía se encuentra la suspensión de la prohibición de otorgar coberturas de crédito a corto plazo con apoyo oficial en los países de la UE y de la OCDE denominados países comercializables o negociables, por considerar que la oferta de seguro disponible para estas operaciones por parte del sector privado ya no está garantizada en la cantidad o profundidad necesarias para asegurar el comercio.
En este contexto, CESCE ha extendido su oferta de cobertura por cuenta del Estado de forma temporal a operaciones de exportación a corto plazo en países de renta alta de la OCDE. Estos riesgos, denominados «negociables» en la normativa europea, normalmente están fuera del ámbito de las Agencias de Crédito Oficial a la Exportación (ECAS), por existir un mercado asegurador privado con capacidad suficiente para cubrir la demanda de este tipo de seguro. Sin embargo, para paliar posibles fallos del mercado privado en estas coberturas en el contexto de la crisis de la COVID-19 y asegurar una oferta suficiente, la Comisión Europea suspendió con carácter temporal la prohibición de cubrir estos riesgos con apoyo de los Estados. Así pues, CESCE ofrece por cuenta del Estado cobertura para los riesgos a corto plazo en países avanzados, complementando así la oferta de las aseguradoras privadas.

De nuevo, se trata de una medida que ha sido utilizada por un número muy limitado de exportadores, posiblemente porque el mercado privado, a pesar de su retracción, sigue dando respuesta a sus necesidades.

\section{CESCE 2020: un año marcado por la COVID-19}

El ejercicio 2020, como no puede ser de otra manera, ha venido marcado por la pandemia de la COVID-19. No se puede resumir la evolución del periodo sin hacer referencia a esta crisis sanitaria mundial, que no solo ha transformado nuestra forma de trabajar y de relacionarnos, sino que, para la Cuenta del Estado de CESCE, también ha determinado las cifras de contratación del año.

Desde el 15 de marzo, día siguiente al decreto del estado de alarma en España, $\square$ 
prácticamente todos los trabajadores ${ }^{2}$ de CESCE nos quedamos en casa, y desde ahí, además de gestionar la actividad habitual, hemos lanzado y gestionado la mayor operación de CESCE desde su creación. Nos referimos a las Líneas de Créditos de Circulante Covid que se han comentado anteriormente.

Esta operación ha definido en gran parte las cifras del año, no solo por su impacto en la contratación global, la concentración por modalidad de cobertura o por destino geográfico, sino también, y como aspecto más reseñable, por el número de operaciones involucradas y el número de empresas beneficiarias a las que ha llegado.

El seguro emitido en 2020 ha alcanzado una cifra de 3.081 millones de euros, frente a 3.091 millones de euros en el ejercicio anterior,

2 Los trabajadores de CESCE han recibido el premio del Club de Exportadores como «Reconocimiento especial a la mejor respuesta empresarial ante la pandemia», premio compartido con los trabajadores de ICO y COFIDES. En palabras del propio Club, "con este premio el jurado quiere reconocer el esfuerzo e implicación personal con el que los equipos de ICO, CESCE y COFIDES han desarrollado su labor durante los últimos meses en apoyo de las empresas españolas con actividad internacional, en un entorno económico extremadamente adverso y con un gran volumen de trabajo sobrevenido, anteponiendo por encima de todo los intereses de la economía española y de su sector exterior» . que se sitúa entre las mayores registradas en los cincuenta años de vida de CESCE. En ella tiene un peso relevante la contratación bajo las Líneas Covid, que suponen un tercio del total.

El valor contractual de las operaciones de exportación que han contado con el apoyo de CESCE en 2020 asciende a 13.209 millones de euros ${ }^{3}$, cifra que refleja el volumen de comercio que se beneficia del apoyo del Estado a través del seguro de CESCE.

El Gráfico 5 demuestra el carácter anticíclico de las coberturas de CESCE, que suele presentar volúmenes de contratación superiores a la media en años de crisis (la excepción fueron los años 2018 y 2019). Otro dato importante que puede verse en este gráfico es cómo el seguro de CESCE presenta un mayor efecto multiplicador en estos años. Esto es así porque en los periodos 2011-2014 y a partir de 2018 las coberturas de créditos de circulante y de avales $\triangleright$

3 Puesto que los créditos asegurados bajo la Línea Covid no son finalistas (no están ligados a una operación de exportación), en estas operaciones en el valor de la operación de exportación se ha reflejado el valor del crédito, por considerar que de alguna forma estas coberturas contribuyen a la actividad internacional de las empresas beneficiarias.

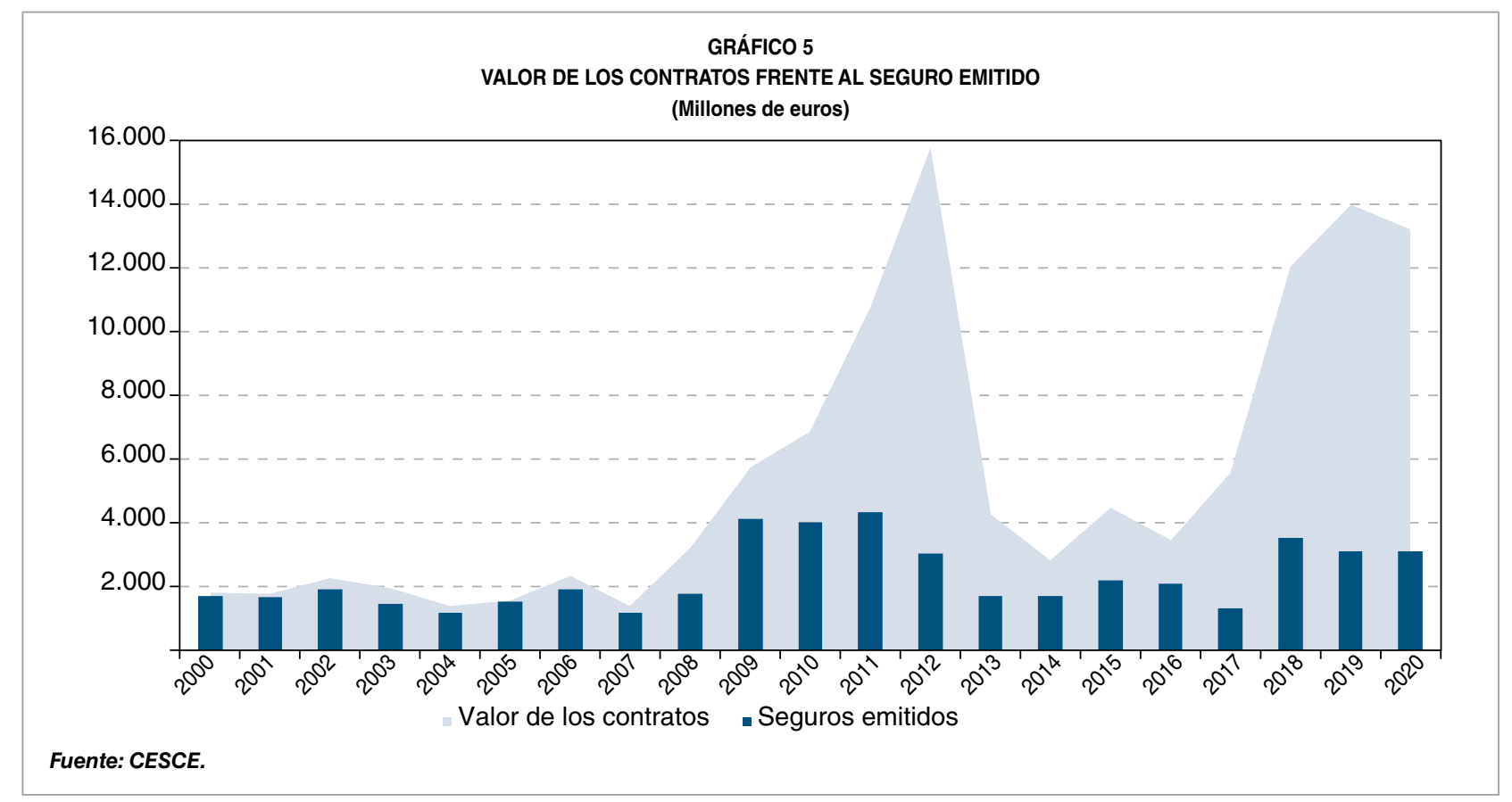




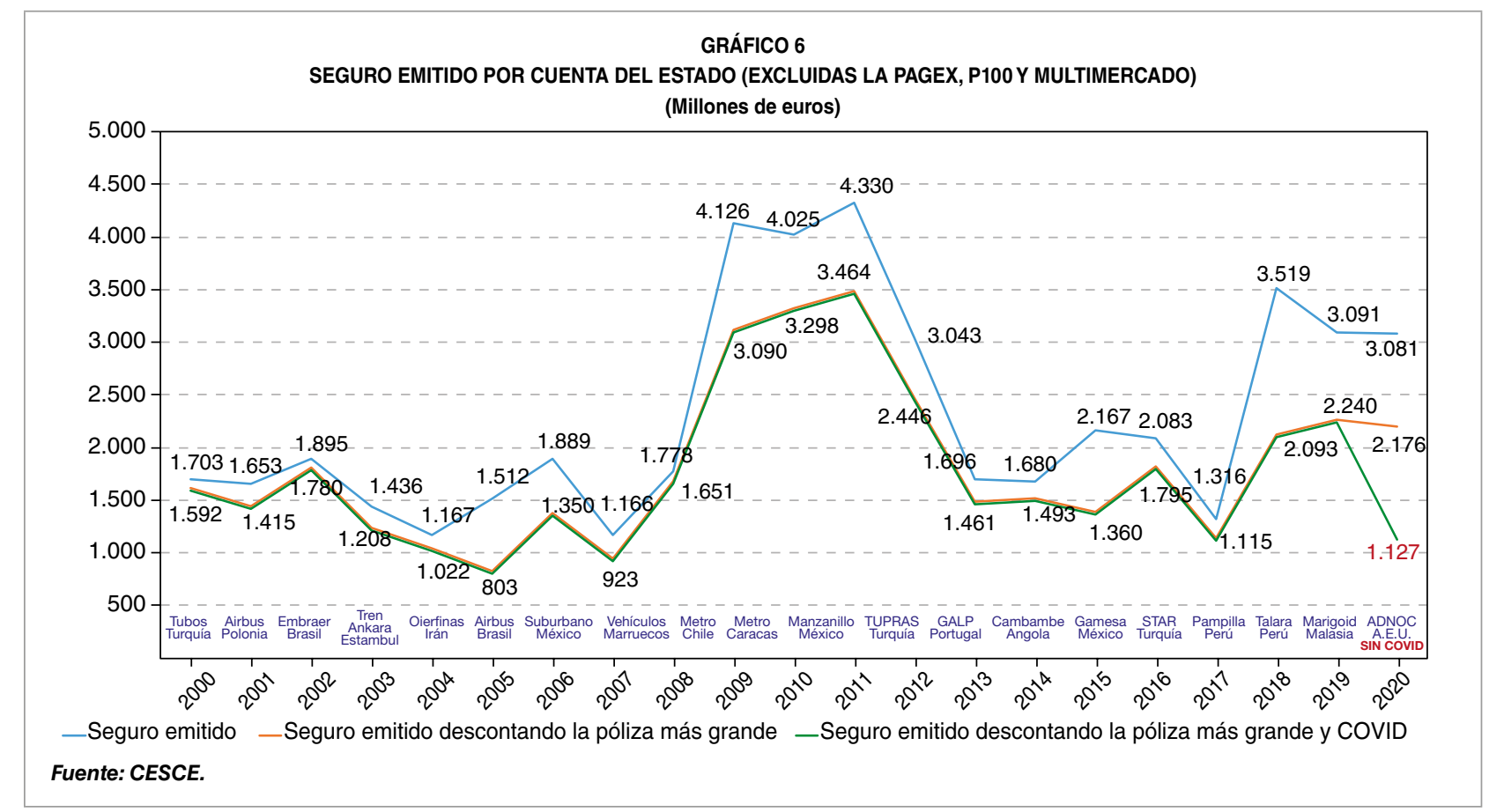

han tenido un mayor protagonismo frente a las coberturas de crédito con deudor extranjero, presentando aquellas un efecto multiplicador mayor.

En el Gráfico 6, por otro lado, se puede ver la evolución del seguro emitido por cuenta del Estado desde 2000. A lo largo de las dos últimas décadas la emisión ha promediado 2.300 millones de euros anuales. Se muestra, además, la evolución del seguro si se elimina el proyecto más grande suscrito cada año, para eliminar la distorsión que en ocasiones origina un único proyecto muy voluminoso sobre la estadística global. En el ejercicio 2020 puede observarse, además, el efecto de la Línea Covid.

En lo que respecta a la distribución por tipo de cobertura, el Crédito Comprador sigue siendo la modalidad más contratada por importes, aunque en el último año seguida muy de cerca por el seguro de Crédito de Circulante (Líneas Covid). Los avales pasan en esta ocasión a tercera posición, lejos de las dos anteriores, posiblemente por la ralentización que la pandemia ha supuesto para la firma de nuevos contratos por parte de los exportadores españoles.

Normalmente, la distribución geográfica de la contratación de cada año viene determinada por las grandes operaciones, cuyos destinos se sitúan habitualmente en cabeza de la lista. Como es lógico, este año la principal concentración de riesgo ha sido España, como consecuencia de la contratación de pólizas de circulante enmarcadas en las Líneas Covid, en las que el riesgo que se asegura es el impago de la empresa española receptora del crédito. Le siguen Emiratos Árabes Unidos, Marruecos, Turquía, Senegal, Argentina y Tanzania.

Al cierre del ejercicio 2020, el valor de los riesgos en cartera ascendía a 16.376 millones de euros, lo que supone un aumento del 1,5\% respecto al cierre del año anterior. Este año España pasa a ocupar la primera posición en la cartera de riesgos, con un $15,4 \%$ de la $D$ 


\section{EL RESPALDO DE CESCE EN TIEMPOS DE COVID...}
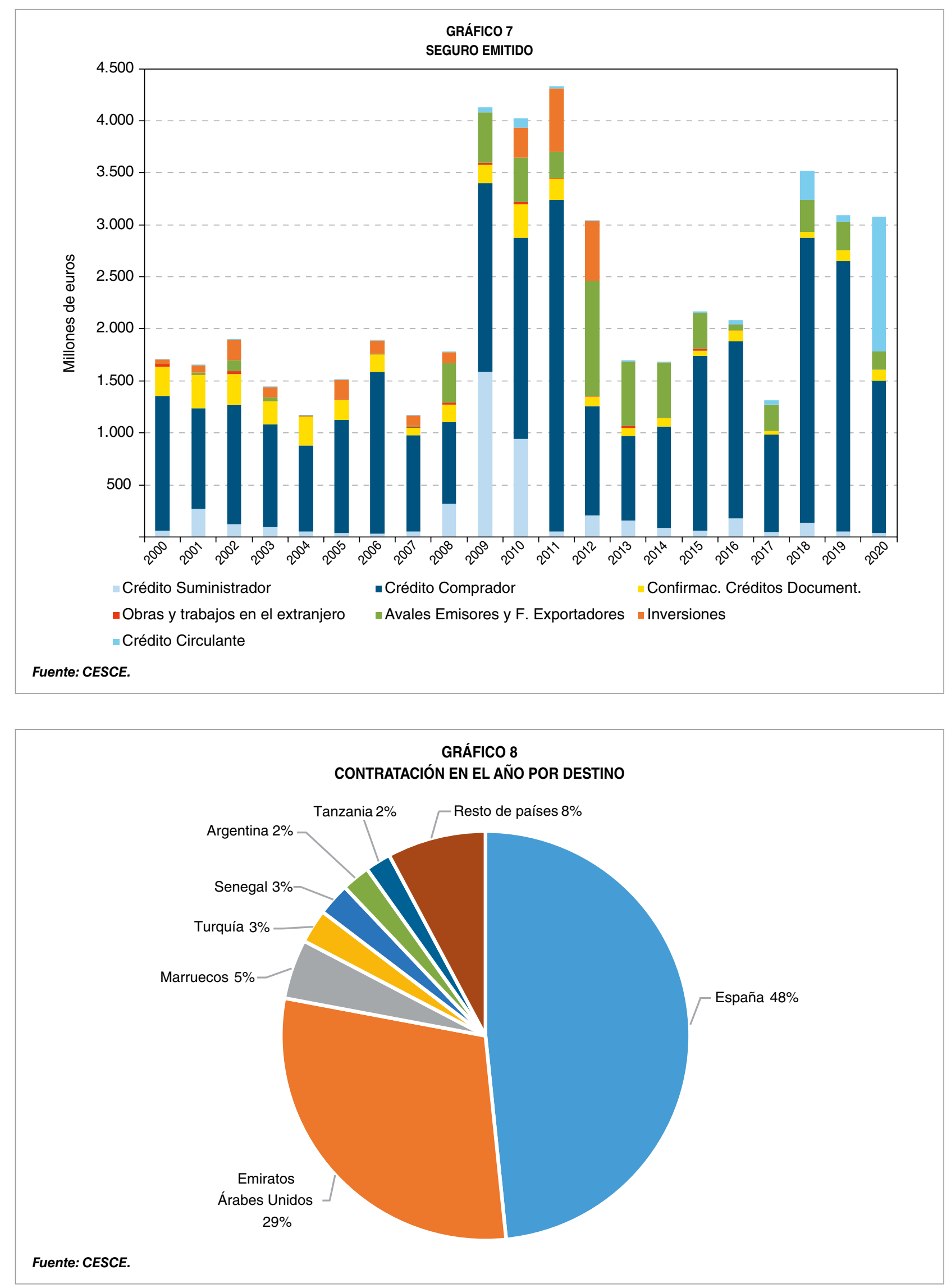
exposición total, debido casi en su totalidad a la contratación de operaciones bajo las Líneas Covid.

También se adelanta Cuba, que pasa a la segunda posición no porque haya habido nueva contratación con este destino - su cifra de riesgo viene de operaciones antiguas y se mantiene, así como también el porcentaje que representa sobre el total $(9,6 \%)$-, sino por la evolución del tipo de cambio, que ha reducido el valor en euros del riesgo con Perú y lo desplaza a tercera posición.

Emiratos Árabes Unidos sube a la cuarta posición, con un 9,1\% del total, seguido de Turquía, que se queda en quinto lugar, con un $7,7 \%$, y de Angola, que, con un $5,8 \%$ del total, pasa del quinto al sexto puesto.
A partir de ahí se producen algunos cambios en este escalafón. Malasia sube a la séptima posición, con un $4,7 \%$, seguida de Bahréin (4,2\%), Omán (3,9\%) y Arabia Saudí (2,9\%). En el Gráfico 9 se puede ver la distribución del riesgo por países.

Como es habitual, los deudores públicos mantienen un peso predominante en la cartera de CESCE, y de hecho lo han incrementado en 2020 , llegando a suponer casi un $64 \%$ del total, mientras que los privados aglutinan el $36 \%$ restante. Dentro de los deudores y garantes públicos, los soberanos suponen aproximadamente la mitad, concentrados principalmente en Angola, Emiratos Árabes Unidos, Argentina, Catar, República Dominicana, Panamá, Ecuador, Camerún, Gabón, Kenia y Omán.

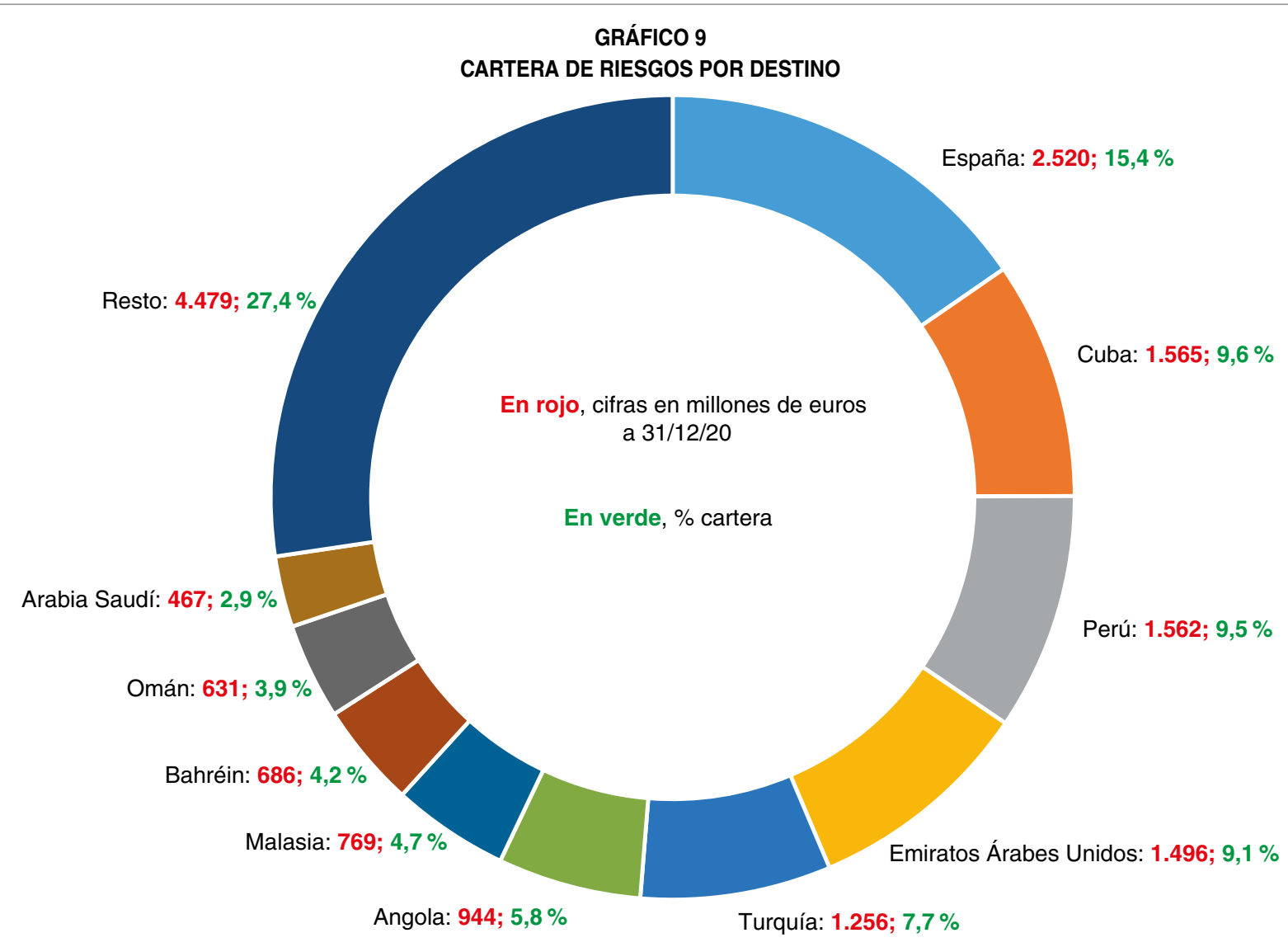

Fuente: CESCE. 


\section{Conclusión}

Desde que se declaró el estado de alarma toda la atención de CESCE y de las autoridades públicas encargadas de impulsar y apoyar la internacionalización de las empresas españolas ha estado centrada en el lanzamiento de nuevas medidas de apoyo tanto para las pymes como para empresas de mayor tamaño, así como en el reforzamiento de medidas ya existentes para dar una respuesta a las nuevas necesidades creadas por el impacto de la pandemia. Esto, en un contexto que también ha cambiado de forma brusca las formas de trabajar, ha supuesto un esfuerzo sin precedentes en la historia de nuestra compañía. En estos meses, además, hemos redoblado nuestros esfuerzos para mejorar y mecanizar los procesos, así como simplificar nuestros productos, con el objetivo de aprovechar las lecciones aprendidas y poder continuar apoyando a un número cada vez mayor de empresas.

Como se ha mencionado, las Líneas Covid I y II han atendido solicitudes de un número enorme de empresas internacionalizadas que no habían trabajado con nosotros con anterioridad y que a partir de esta experiencia conocen los productos de CESCE y las posibilidades que brindan a la empresa que exporta 0 invierte en el exterior.

Por último, señalar que no habríamos podido atender el extraordinario número de solicitudes que se ha producido sin la colaboración de los equipos de los bancos, que canalizan esa financiación con cobertura hacia las empresas. La intensa relación de trabajo ha propiciado también un mayor diálogo, que redundará, sin duda, en la mejora y adaptación de los productos para responder también a las necesidades de los bancos.

\section{Bibliografía}

Real Decreto-ley 8/2020, de 17 de marzo, de medidas urgentes extraordinarias para hacer frente al impacto económico y social del COVID-19. Boletín Oficial del Estado, n.․ 73, de 18 de marzo de 2020, pp. 25853 a 25898. https://www.boe.es/eli/ es/rdl/2020/03/17/8/con

Real Decreto-ley 25/2020, de 3 de julio, de medidas urgentes para apoyar la reactivación económica y el empleo. Boletín Oficial del Estado, n.ำ 185, de 6 de julio de 2020, pp. 47684 a 47742 . https:// www.boe.es/eli/es/rdl/2020/07/03/25/con

Reglamento (UE) n.. 651/2014 de la Comisión, de 17 de junio de 2014, por el que se declaran determinadas categorías de ayudas compatibles con el mercado interior en aplicación de los artículos 107 y 108 del Tratado. Diario Oficial de la Unión Europea. https://boe.es/doue/2014/187/ L00001-00078.pdf

Unión Europea (2020). Comunicación (2020/C 911/01) de la Comisión, de 20 de marzo de 2020, sobre el Marco Temporal relativo a las medidas de ayuda estatal destinadas a respaldar la economía en el contexto del actual brote de COVID-19. Diario Oficial de la Unión Europea. https://eur-lex.europa.eu/legal-content/ES/TXT/ $\mathrm{PDF} /$ ?uri=CELEX:52020XC0320(03)\&from=ES 
